Systematic Review

\title{
A Multivariable Prediction Model for the Chronification of Non-traumatic Shoulder Pain: A Systematic Review
}

Filip Struyf, PhD ${ }^{1,2}$, Jacques Geraets, $\mathrm{PhD}^{3}$, Suzie Noten, $\mathrm{MSc}^{1,2}$, Mira Meeus, $\mathrm{PhD}^{1,2,4}$, and Jo Nijs, PhD $2,5,6$

\begin{abstract}
From: 'Department of Rehabilitation Sciences and Physiotherapy, Faculty of Medicine and Health Sciences, University of Antwerp, Belgium; '2Pain in Motion Research Group, www.paininmotion.be; ${ }^{3}$ Faculty of Health and Technique, University College Zuyd, Heerlen, the Netherlands; ${ }^{4}$ Department of Rehabilitation Sciences and Physiotherapy, Faculty of Medicine and Health Sciences, Ghent University, Ghent, Belgium; ${ }^{5}$ Departments of Human Physiology, Rehabilitation Sciences and

Physiotherapy, Faculty of Physical Education and Physiotherapy, Vrije Universiteit Brussel, Belgium;

${ }^{6}$ Department of Physical Medicine and Physiotherapy, University Hospital Brussels, Belgium

Address Correspondence: Filip Struyf, PhD

Department of Rehabilitation Sciences and Physiotherapy, Faculty of Medicine and Health Sciences

University of Antwerp, Belgium Universiteitsplein 1 2610 Wilrijk, Belgium E-mail:

Filip.struyf@uantwerpen.be
\end{abstract}

Disclaimer: There was no external funding in the preparation of this manuscript. Conflict of interest: Each

author certifies that he or she, or a

member of his or her immediate family, has no commercial association

(i.e., consultancies, stock ownership,

equity interest, patent/licensing arrangements, etc.) that might pose a conflict of interest in connection with the submitted manuscript.

Manuscript received: 03-27-2015 Revised manuscript received: 07-31-2015 Accepted for publication: 08-11-2015

Free full manuscript: www.painphysicianjournal.com
Background: Shoulder pain is the third most common musculoskeletal complaint and many patients have an unfavorable outcome with long-term disability. Only $50 \%$ of all new episodes of shoulder pain show complete recovery within 6 months. Little is known about factors that contribute to chronicity of shoulder pain, although such information is needed for the management of patients with acute and sub-acute shoulder pain.

Objective: To systematically review the literature for prognostic factors which are potential predictors for either recovery or chronification in patients with acute and sub-acute nontraumatic shoulder pain.

Study Design: Systematic review.

Setting: This systematic review examined all studies involving the prognosis of shoulder pain patients.

Methods: This systematic review was reported following the guidelines outlined in the Preferred Reporting Items for Systematic Reviews and Meta-Analyses (PRISMA). Two reviewers independently scored the methodological quality of the selected studies. Due to heterogeneity of studies, a best-evidence synthesis of the available prognostic factors was provided.

Results: Nine studies met our inclusion criteria and were included in this systematic review. There is strong evidence that high scores on the Shoulder Pain and Disability Index (SPADI), high scores on shoulder pain severity, and a long duration of complaints are factors that contribute to the chronification of shoulder pain. Moderate evidence was found supportive for other prognostic factors that enhance chronification, like being male, being over 55 years of age, having poor general health, having a gradual onset of complaints, a large amount of sick leave, the perception of high job demand, the perception of low social support, and the amount of visits to a health care professional. Also moderate evidence exists regarding factors that contributed to a reduced possibility of chronification: an active treatment policy and not taking medication on regular basis.

Limitations: The large variability in definitions of shoulder pain, and patient selection bias. In addition, there is a paucity of strong longitudinal prospective studies.

Conclusion: This systematic review found evidence that high scores on the SPADI questionnaire, more shoulder pain, and a longer duration of complaints are associated with chronification of shoulder pain. In order to reduce chronification, clinicians can use the International Classification of Functioning based model presented here that could aid their decision-making.

Key words: Shoulder pain, prognostic factors, systematic review, prognosis, assessment

Pain Physician 2016; 19:1-10 
( houlder pain is the third most common musculoskeletal disorder, with incidence rates up to $2.5 \%$ and prevalence figures that range from $6.9 \%$ to $26 \%$ for point prevalence, which rise up to $66.7 \%$ for lifetime prevalence in the general population (1-3). About half of all shoulder pain patients show complete recovery within 6 months after injury, and an additional $10 \%$ recovers during the following 6 months (4-6). However, a large patient group reports persistent shoulder pain with high rates of sick leave and therefore contributes to more than $80 \%$ of the total economic cost due to shoulder pain (7).

The medical, personal, and socio-economic impact of shoulder pain is well known, but little is known about the factors that contribute to chronicity (2). Knowledge of prognostic factors that can help us predict chronification of shoulder complaints are essential in order to differentiate patients with a good prognosis and patients at risk for long-term pain or disability. The latter may also support clinicians in their decision-making process regarding treatment and referral of patients.

The most often reported clinical pathologies related to chronic shoulder pain are rotator cuff disorders, adhesive capsulitis of the shoulder, and glenohumeral osteo-arthritis, accounting for a largest portions of all shoulder pain pathologies (8). In addition, rotator cuff disorders, and more specifically supraspinatus tendinopathies, are the most common cause of chronic shoulder pain (9). Indeed, the rotator cuff is the main dynamic stabilizer of the shoulder joint, thereby creating centering of the humeral head into the glenoid. An injury or weakness of the rotator cuff can therefore cause additional instability, triggering other muscles, such as the long head of the biceps, to co-activate and stabilize the glenohumeral joint. It is not suprising that supraspinatus tendinopathies are frequenlty associated with the affectation of the long head of the biceps tendon (9). In addition, adhesive capsulitis of the shoulder is a pathology with high prevelance rates (up to $5.3 \%$ in the general population) that is characterized by a long duration of symptoms and consequenlty accounts for a large portion of chronic shoulder pain patients (10-12).

Many suggestions for prognostic factors for persisting musculoskeletal shoulder pain are reported in the literature, such as the duration of sick leave at baseline, high rate of shoulder disability, more concomitant neck or back pain, and high pain intensity (7). Musculoskeletal pain differs from chronic neuropathic pain as the latter is pain arising as a direct consequence of a lesion or disease affecting the somatosensory system
(13). To the best of our knowledge, a recent systematic literature review addressing the prognostic factors for chronicity in musculoskeletal shoulder pain patients is currently unavailable. Consequently, the purpose of this study was to systematically review the prognostic factors that contribute to the transition of acute and sub-acute to chronic shoulder pain. In order to be of practical use for clinicians working with shoulder pain patients, these factors were collected within a practical framework based on the International Classification of Functioning (ICF) (www.who.int/classifications/icf/).

\section{Methods}

This systematic review was reported following the guidelines outlined in the Preferred Reporting Items for Systematic Reviews and Meta-Analyses (PRISMA) (14). Methods of the analysis and inclusion criteria were specified in advance and not changed post-hoc.

\section{Eligibility Criteria}

Keywords were derived using the PICOS-method, and Medical Subjects Headings (MeSH) terms were used where possible. Inclusion criteria were described in PICOS terminology: Patient (P), Intervention (I), Comparison (O), Outcome (O), and Study design (S). This systematic review attempted to select those articles, which described baseline prognostic parameters (I) in patients with acute and sub-acute non-traumatic shoulder pain (P), which could be predictive for chronicity (O) or recovery (C). For this purpose, only prospective cohort studies (S) were included.

\section{Information Sources and Search Strategy}

A systematic literature search was conducted until December 2014. Both the PubMed and EBSCO databases were searched to identify relevant articles. The following key words were used: "shoulder pain" (MeSH), "shoulder impingement syndrome" (MeSH), "shoulder complaint," "rotator cuff suffering," "rotator cuff pathology," "shoulder pathology," "prognosis" (MeSH), "prognostic factor," "prognostic value," and "prognostic indicator."

\section{Study Selection}

Studies met the selection criteria noted in Table 1.

\section{Qualification of Searcher / Rater}

Based on the eligibility criteria, all articles were screened in a standardized manner for both title and abstract to retrieve relevant articles. The rater has a 
Table 1. Study selection criteria.

\begin{tabular}{|c|c|}
\hline Inclusion criteria & Exclusion criteria \\
\hline $\begin{array}{l}\text { Patients suffering from acute or sub-acute non-traumatic shoulder } \\
\text { pain; }\end{array}$ & $\begin{array}{l}\text { Shoulder pain due to traumatic or systemic diseases (such as } \\
\text { rheumatoid arthritis), post-operative patients; }\end{array}$ \\
\hline Prospective cohort studies; & Generalization of shoulder, arm, hand, and neck symptoms; \\
\hline Studies in English or Dutch; & Case reports, reviews, letters-to-the editor, clinical trials, and \\
\hline Full text available; & retrospective studies; \\
\hline $\begin{array}{l}\text { Studies with a total score of } 7 / 10 \text { or higher on the methodological } \\
\text { quality assessment; }\end{array}$ & $\begin{array}{l}\text { Studies with a total score of } 6 / 10 \text { or lower on the methodological } \\
\text { quality assessment; }\end{array}$ \\
\hline Studies needed to report odds ratios; & Not reporting odds ratios; \\
\hline At least 3 months follow-up period in order to determine chronicity. & Less than 3 months follow-up. \\
\hline
\end{tabular}

Table 2. Results of the methodological assessment of prognostic cohort studies on shoulder disorder.

\begin{tabular}{|l|c|c|c|c|c|c|c|c|c|c|c|c||}
\hline First author & $\mathbf{1}$ & $\mathbf{2}$ & $\mathbf{3}$ & $\mathbf{4}$ & $\mathbf{5}$ & $\mathbf{6}$ & $\mathbf{7}$ & $\mathbf{8}$ & $\mathbf{9}$ & $\mathbf{1 0}$ & Quality score & Level of Evidence \\
\hline Bonde et al, 2003 (17) & 1 & 0 & 1 & 1 & 0 & 1 & 1 & 1 & 1 & 1 & 8 & $\mathrm{~A} 2$ \\
\hline Brox et al, 1996 (18) & 1 & 1 & 1 & 1 & 0 & 1 & 0 & 1 & 1 & 1 & 8 & $\mathrm{~B}$ \\
\hline Kuijpers et al, 2006 (6) & 1 & 1 & 1 & 1 & 0 & 1 & 0 & 1 & 1 & 1 & 8 & $\mathrm{~B}$ \\
\hline Kuijpers et al, 2006 (7) & 1 & 1 & 1 & 1 & 0 & 1 & 0 & 1 & 1 & 1 & 8 & 8 \\
\hline Reilingh et al, 2008 (19) & 1 & 1 & 1 & 1 & 0 & 1 & 0 & 1 & 1 & 1 & 8 & B \\
\hline Thomas et al, 2005 (20) & 1 & 0 & 0 & 1 & 0 & 1 & 1 & 1 & 1 & 1 & 7 & A2 \\
\hline Luime et al, 2005 (2) & 1 & 1 & 0 & 1 & 0 & 1 & 1 & 1 & 1 & 1 & 8 & A2 \\
\hline Luime et al, 2004 (1) & 1 & 0 & 1 & 1 & 0 & 1 & 1 & 1 & 1 & 1 & 8 & A2 \\
\hline Van der Windt et al, 2007 (21) & 1 & 1 & 1 & 1 & 0 & 0 & 0 & 1 & 1 & 1 & 7 & B \\
\hline
\end{tabular}

Questions: 1) Is the study population clearly defined?; 2) Can selection bias sufficiently be excluded?; 3) Is exposure to treatment clearly defined and is the methodology for exposure adequate?; 4) Is the outcome clearly defined and is the method for assessing the outcome adequate?; 5) Is the outcome determined blind for exposure status?; 6) Is there a sufficient follow-up period?; 7) Can selective loss-to-follow-up be excluded?; 8) Are the most important confounders or prognostic factors identified and are they adequately taken into account in the analysis?; 9) Are the results of the study valid and applicable?; 10) Are the results generalizable to the Dutch situation?

PhD in rehabilitation sciences and physiotherapy, with a dissertation regarding shoulder pain. The rater has published several systematic reviews.

\section{Risk of Bias in Individual Studies}

The methodological quality was assessed by using the Central Counseling Institution (CBO) guidelines for cohort studies (www.cbo.nl). The CBO guidelines for cohort studies include the following analysis: Is the study population clearly defined? Can selection bias sufficiently be excluded? Is exposure to treatment clearly defined and is the methodology for exposure adequate? Is the outcome clearly defined and is the method for assessing the outcome adequate? Is the outcome determined blind for exposure status? Is there a sufficient follow-up period? Can selective loss-to-follow-up be excluded? Are the most important confounders or prognostic factors identified and are they adequately taken into account in the analysis? Are the results of the study valid and applicable? Are the results generaliz- able to the Dutch situation? Consequently, these items were scored positive (sufficient information), negative (sufficient information, but potential bias due to inadequate design or conduct present), or kept blank (insufficient information): population, selection bias, exposure, outcome, blinding of researchers, follow-up, loss-to-follow-up, confounders and prognostic factors, validity, and generalization (Table 2 ). If necessary a second opinion was consulted.

\section{Data Extraction}

After selecting all relevant studies, data was extracted regarding study design, study population, outcome, follow-up, prognostic factors for shoulder pain, and strength of association (odds ratios). A negative prognostic factor was defined as a predictor of poor outcome. In studies that included both healthy subjects and patients with shoulder complaints, only the data of the shoulder patients were included in this synthesis.

Moderate evidence was defined as one prospec- 
tive cohort study of good methodological quality that reports a significant prognostic value. Strong evidence was defined as at least 2 independent studies of good quality that reported a significant prognostic value.

\section{Results}

\section{Selection of Studies}

The results of our search strategy are presented in Fig. 1. A total of 9 prospective cohort studies met the selection criteria and were included in this systematic review.

\section{Study Characteristics}

The results of the methodological assessment are presented in Table 2. Detailed information regarding the characteristics of the included studies is summarized in an evidence table (Table 3). Both studies of Luime et al $(1,2)$ addressed the same data set, of which the 2005 publication covered a one-year longer follow-up than the 2004 publication. Therefore, only the Luime et al (2) was included in the literature synthesis. Likewise, the studies of Kuijpers et al (6), Kuijpers et al (7), Van der Windt et al (21), and Reilingh et al (19) were based on the same dataset, focusing on different study aims. In this systematic review, description of these results are summarized and reported as on study in the evidence table (Table 3). All studies that obtained an acceptable internal validity score $(\geq 7 / 10)$ were used for further appraisal. The heterogeneity of the prognostic factors identified and outcome measures used in the included studies precluded statistical pooling of the results.

Table 4 shows the prognostic factors that were reported as being statistically significant and the amount of studies that reported such significant odds ratios.

\section{Discussion}

\section{Summary of Evidence}

This systematic review found strong evidence that a long duration of complaints (> 3 months), higher scores on the SPADI (disability), and the intensity of shoulder pain were prognostic factors for chronification of non-traumatic shoulder pain. Moderate evidence was

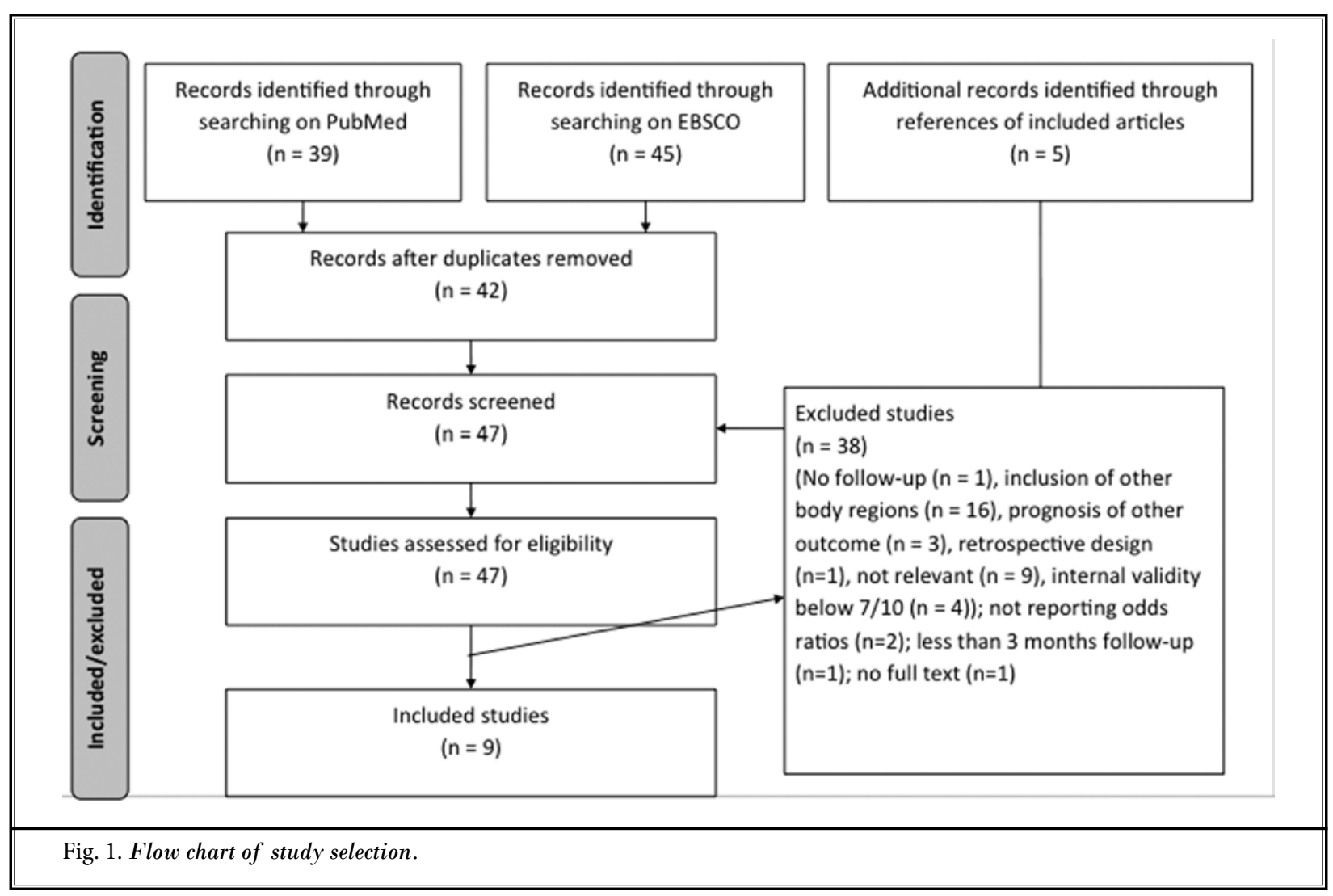


Table 3. Evidence table of prognostic studies.

\begin{tabular}{|c|c|c|c|c|c|}
\hline Study characteristics & Bonde et al 2003 & $\begin{array}{c}\text { Luime et al } \\
2005\end{array}$ & $\begin{array}{c}\text { Thomas et al } \\
2005\end{array}$ & $\begin{array}{l}\text { Brox et al } \\
1996\end{array}$ & $\begin{array}{l}\text { Kuypers et al 2006, } \\
\text { Van der Windt } 2007 ; \\
\text { Reilingh et al, } 2008\end{array}$ \\
\hline Study population & $\begin{array}{c}\text { workers with } \\
\text { clinical signs of } \\
\text { shoulder tendonitis }\end{array}$ & $\begin{array}{l}\text { workers of } \\
\text { nursing and/or } \\
\text { elderly homes } \\
\text { with shoulder } \\
\text { and neck } \\
\text { compliants } \\
\end{array}$ & $\begin{array}{l}\text { patients } \\
\text { consulting in } \\
\text { primary care for } \\
\text { shoulder pain (2 } \\
\text { RCTs: NL \& UK) }\end{array}$ & $\begin{array}{l}\text { patients } \\
\text { with rotator } \\
\text { tendinosis }\end{array}$ & $\begin{array}{l}\text { patients with a first episode } \\
\text { of shoulder pain }\end{array}$ \\
\hline Mean age $(\mathrm{SD})$ & $\begin{array}{l}46 \text { (8.9) (completed } \\
\text { follow) }\end{array}$ & $\begin{array}{l}41.6(8.9) \\
\text { (completed } \\
\text { follow-up) } \\
\end{array}$ & $\begin{array}{c}58.8(10.5)(\mathrm{NL})- \\
57.5(13.4)(\mathrm{UK}) \\
\quad \text { (at baseline) } \\
\end{array}$ & $\begin{array}{c}48(11) \\
\text { (completed } \\
\text { follow-up) } \\
\end{array}$ & 51 (14) (at baseline) \\
\hline $\mathrm{n}$ (at baseline) & 167 & 769 & $\begin{array}{c}109 \text { (NL) - } 207 \\
(\mathrm{UK})\end{array}$ & 125 & 587 \\
\hline Women & $\begin{array}{l}61 \% \text { (completed } \\
\text { follow-up) }\end{array}$ & $\begin{array}{l}\text { 84\% (completed } \\
\text { follow-up) }\end{array}$ & $\begin{array}{l}58 \%(\mathrm{NL})- \\
53 \%(\mathrm{UK})(\text { at } \\
\text { baseline) }\end{array}$ & $\begin{array}{c}44 \% \\
\text { (complete } \\
\text { follow-up) }\end{array}$ & $50 \%$ (at baseline) \\
\hline Therapy & 1 & $\begin{array}{c}\text { general } \\
\text { practitioner, } \\
\text { physiotherapist, } \\
\text { medical } \\
\text { specialist }\end{array}$ & $\begin{array}{c}\text { local intra- } \\
\text { articular } \\
\text { injections (NL) } \\
\text { \& subacromial } \\
\text { injections (UK); } \\
\text { both versus } \\
\text { physiotherapy }\end{array}$ & $\begin{array}{l}\text { supervised } \\
\text { exercise } \\
\text { regime; } \\
\text { arthroscopic } \\
\text { acromion } \\
\text { resection; } \\
\text { placebo laser }\end{array}$ & $\begin{array}{l}\text { standardized treatment } \\
\text { (information, paracetamol, } \\
\text { non-steroidal anti- } \\
\text { inflammatory drugs, } \\
\text { corticosteroid injection or } \\
\text { physiotherapy) }\end{array}$ \\
\hline $\begin{array}{l}\text { Follow-up period (\% completed } \\
\text { follow-up) }\end{array}$ & 3 years $(74 \%)$ & 2 years $(65 \%)$ & $\begin{array}{c}18 \text { months (UK), } \\
12 \text { months (NL) } \\
\text { (84\% both studies } \\
\text { combined) }\end{array}$ & $\begin{array}{c}6 \text { months } \\
(91 \%)\end{array}$ & 6 months $(92 \%)$ \\
\hline \multicolumn{6}{|l|}{ Personal factors (OR) } \\
\hline Gender (male) & 1.0 & & $6.06^{*}$ & & 0.9 \\
\hline Gender (female) & 0.8 & & & & \\
\hline Age (> 55yrs) & $3.8^{*}$ & & & & \\
\hline Age (45-55 yrs) & 2.0 & & & & \\
\hline Age (<45 yrs) & 1.0 & & & & \\
\hline \multicolumn{6}{|l|}{ External factors (OR) } \\
\hline Education (> 3 years) & & & & 1.6 & 0.7 \\
\hline Education (<3 years) & & & & 1 & \\
\hline general practitioners visits & & $5.84^{*}$ & & & \\
\hline sick leave duration & & $4.18^{*}$ & & & \\
\hline on sick leave(yes > 1 week) & & & & 1 & $3.3^{*}(\mathrm{n}=350$ working cases $)$ \\
\hline on sick leave(no < 1 week) & & & & $4.3^{*}$ & $1.8^{\star}(\mathrm{n}=350$ working cases $)$ \\
\hline \multicolumn{6}{|l|}{ Physical factors (OR) } \\
\hline duration of complaints $>3$ months & & $4.06^{*}$ & 0.25 per month ${ }^{*}$ & & $3.5^{*}$ \\
\hline poor general health & & $1.27^{*}$ & & & \\
\hline Baseline pain score & & & $\begin{array}{l}0.19 \text { per point on } \\
\text { VAS or NRS }\end{array}$ & & $1.2^{*}$ \\
\hline Baseline disability score & & & $\begin{array}{l}0.23 \text { per point on } \\
\text { SDQ }^{*}\end{array}$ & & $1.0^{*}$ \\
\hline gradual onset of complaints & & & 3.32 & & $2.2^{*}$ \\
\hline
\end{tabular}


Pain Physician: February 2016: 19:1-10

Table 3 (cont.). Evidence table of prognostic studies.

\begin{tabular}{|c|c|c|c|c|c|}
\hline Study characteristics & Bonde et al 2003 & $\begin{array}{c}\text { Luime et al } \\
2005\end{array}$ & $\begin{array}{c}\text { Thomas et al } \\
2005\end{array}$ & $\begin{array}{c}\text { Brox et al } \\
1996\end{array}$ & $\begin{array}{l}\text { Kuypers et al 2006 } \\
\text { Van der } \\
\text { Reilingh et al, } 2008\end{array}$ \\
\hline $\begin{array}{l}\text { Side of shoulder disorder } \\
\text { (dominant) }\end{array}$ & 0.8 & & 4.24 & & 1.2 \\
\hline $\begin{array}{l}\text { Side of shoulder disorder } \\
\text { (non-dominant) }\end{array}$ & 1.0 & & & & \\
\hline previous episodes of shoulder pain & & & & & 1.3 \\
\hline previous episodes of neck pain & & & & & 1.4 \\
\hline other diseases & & & & 1 & \\
\hline no other diseases & & & & 1.5 & \\
\hline $\begin{array}{l}\text { concomitant neck pain (or high } \\
\text { back pain) }\end{array}$ & & & 2.76 & & \\
\hline $\begin{array}{l}\text { concomitant psychological } \\
\text { complaints }\end{array}$ & & & & & 1.5 \\
\hline $\begin{array}{l}\text { pressure aglometry threshold }(< \\
25 \text { th centile) }\end{array}$ & 1.1 & & & & \\
\hline $\begin{array}{l}\text { pressure aglometry threshold ( } \geq \\
25 \text { th centile) }\end{array}$ & 1.0 & & & & \\
\hline \multicolumn{6}{|l|}{ Causes (OR) } \\
\hline unexpected movement & & & & & 1.3 \\
\hline $\begin{array}{l}\text { strain/overuse due to usual } \\
\text { activities }\end{array}$ & & & & & 1.3 \\
\hline $\begin{array}{l}\text { strain/overuse due to unusual } \\
\text { activities }\end{array}$ & & & & & 0.6 \\
\hline injury & & & & & 2.4 \\
\hline unknown cause & & & & & 0.9 \\
\hline \multicolumn{6}{|l|}{ Therapy (OR) } \\
\hline Not regular medication & & & & $5.3^{*}$ & \\
\hline Regular pain medication & & & & 1 & \\
\hline Not active treatment & & & & 1 & \\
\hline active treatment & & & & $5.4^{*}$ & \\
\hline \multicolumn{6}{|l|}{ Work/job (OR) } \\
\hline shoulder movements/minute $(>15)$ & 0.6 & & & & \\
\hline shoulder movements/minute $(\leq 15)$ & 1.0 & & & & \\
\hline repetitive movements (yes) & 1.0 & & & & \\
\hline repetitive movements (no) & 1.0 & & & & \\
\hline $\begin{array}{l}\text { Perceived job demand ( }>75 \text { th } \\
\text { centile - high) }\end{array}$ & $4.1^{*}$ & & & & \\
\hline $\begin{array}{l}\text { Perceived job demand (25th to } \leq \\
75 \text { th centile - moderate) }\end{array}$ & 1.8 & & & & \\
\hline $\begin{array}{l}\text { Perceived job demand }(\leq 25 \text { th } \\
\text { centile - low })\end{array}$ & 1.0 & & & & \\
\hline $\begin{array}{l}\text { Perceived job control (> 75th } \\
\text { centile - high) }\end{array}$ & 1.0 & & & & \\
\hline $\begin{array}{l}\text { Perceived job control (25th to } \leq \\
75 \text { th centile - moderate) }\end{array}$ & 1.8 & & & & \\
\hline
\end{tabular}


Table 3 (cont.). Evidence table of prognostic studies.

\begin{tabular}{|c|c|c|c|c|c|}
\hline Study characteristics & Bonde et al 2003 & $\begin{array}{c}\text { Luime et al } \\
2005\end{array}$ & $\begin{array}{c}\text { Thomas et al } \\
2005\end{array}$ & $\begin{array}{c}\text { Brox et al } \\
1996\end{array}$ & $\begin{array}{l}\text { Kuypers et al 2006 } \\
\text { Van der Windt } 2007 ; \\
\text { Reilingh et al, } 2008\end{array}$ \\
\hline $\begin{array}{l}\text { Perceived job control }(\leq 25 \text { th } \\
\text { centile - low) }\end{array}$ & 2.5 & & & & \\
\hline $\begin{array}{l}\text { Perceived social support ( }>75 \text { th } \\
\text { centile - high) }\end{array}$ & 1.0 & & & & \\
\hline $\begin{array}{l}\text { Perceived social support ( } 25 \text { th to } \leq \\
75 \text { th centile - moderate) }\end{array}$ & 3.1 & & & & \\
\hline $\begin{array}{l}\text { Perceived social support }(\leq 25 \text { th } \\
\text { centile - low) }\end{array}$ & $6.8^{*}$ & & & & \\
\hline Use of shoulder force (> 10\% MVC) & 0.5 & & & & \\
\hline Use of shoulder force ( $\leq 10 \% \mathrm{MVC})$ & 1.0 & & & & \\
\hline overhead work (often/very often) & & & & 1 & \\
\hline overhead work (sometimes/never) & & & & 1 & \\
\hline task cycle duration ( $<20$ seconds) & 1.0 & & & & \\
\hline task cycle duration ( $\geq 20$ seconds) & 1.0 & & & & \\
\hline \multicolumn{6}{|l|}{ Phychosocial (OR) } \\
\hline depression & & & & & 3.0 \\
\hline pain catastrophizing & & & & & 1.4 \\
\hline somatization & & & & & 2.5 \\
\hline kinesiophobia & & & & & 1.5 \\
\hline coping with pain & & & & & 2.2 \\
\hline emotional distress (yes) & & & & 1 & \\
\hline emotional distress (no) & & & & 1 & \\
\hline internal locus of control & & & & 1.4 & 1.4 \\
\hline no internal locus of control & & & & 1 & 1.3 \\
\hline intrinsic effort personality (yes) & 1.2 & & & & \\
\hline intrinsic effort personality (no) & 1.0 & & & & \\
\hline
\end{tabular}

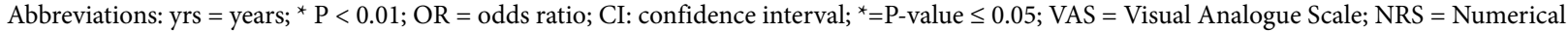

Rating Scale; SDQ = Shoulder Disability Questionnaire

found for other prognostic factors like male gender, being over 55 years of age, having a poor general health, a gradual onset of complaints, longer duration of sick leave, the perception of high job demand, low perceived social support, and the number of general practitioners visits. Prognostic factors that reduce the possibility of chronification included the presence of an active treatment policy and not taking pain medication on a regular basis. Equally important were factors that did not prove to be of any prognostic value, such as the side at which the shoulder pain is present (dominant or non-dominant), the patients' education, previous episodes of shoulder or neck pain, concomitant neck pain, the presence of other diseases, a change in pressure point thresholds, any cause of the shoulder complaint, repetitive movements, the frequency and duration of shoulder movement per minute, perceived job control, the use of shoulder force, the amount of overhead work, and psychosocial factors.

The aim of this study was not only to review the results of different studies, but also to translate the results into a practical framework useful in clinical prac- 
Table 4. Prognostic factors that were reported as being statistically significant ( $\left.{ }^{*}\right)$; - stands for prognostic factors which enhance the possibility of chronification; + stands for prognostic factors that reduce the possibility of chronification.

\begin{tabular}{|c|c|c|c|}
\hline Prognostic factor & \# of datasets & Odds ratio interval & Evidence \\
\hline - Gender (male) & 4 & $0.9-6.06^{*}$ & MODERATE \\
\hline - Age (> 55yrs) & 1 & $3.8^{*}$ & MODERATE \\
\hline - General practitioners visits & 1 & $5.84^{*}$ & MODERATE \\
\hline - Sick leave duration & 1 & $4.18^{\star}$ & MODERATE \\
\hline - Duration of complaints $>3$ months & 3 & $3.5^{\star}-4.06^{*} ; 0.25 /$ month $^{*}$ & STRONG \\
\hline - Poor general health & 1 & $1.27^{*}$ & MODERATE \\
\hline - Baseline pain score & 2 & $0.19 /$ point on VAS/NRS ${ }^{*} ; 1.2^{*}$ & STRONG \\
\hline - Baseline disability score & 2 & 0.23 per point on $\mathrm{SDQ}^{*} ; 1.0^{*}$ & STRONG \\
\hline - Gradual onset of complaints & 2 & $2.2^{*}-3.32$ & MODERATE \\
\hline + Not regular medication & 1 & $5.3^{*}$ & MODERATE \\
\hline+ Active treatment & 1 & $5.4^{*}$ & MODERATE \\
\hline - Perceived job demand (> 75th centile - high) & 1 & $4.1^{*}$ & MODERATE \\
\hline - Perceived social support ( $\leq 25$ th centile - low) & 1 & $6.8^{\star}$ & MODERATE \\
\hline
\end{tabular}

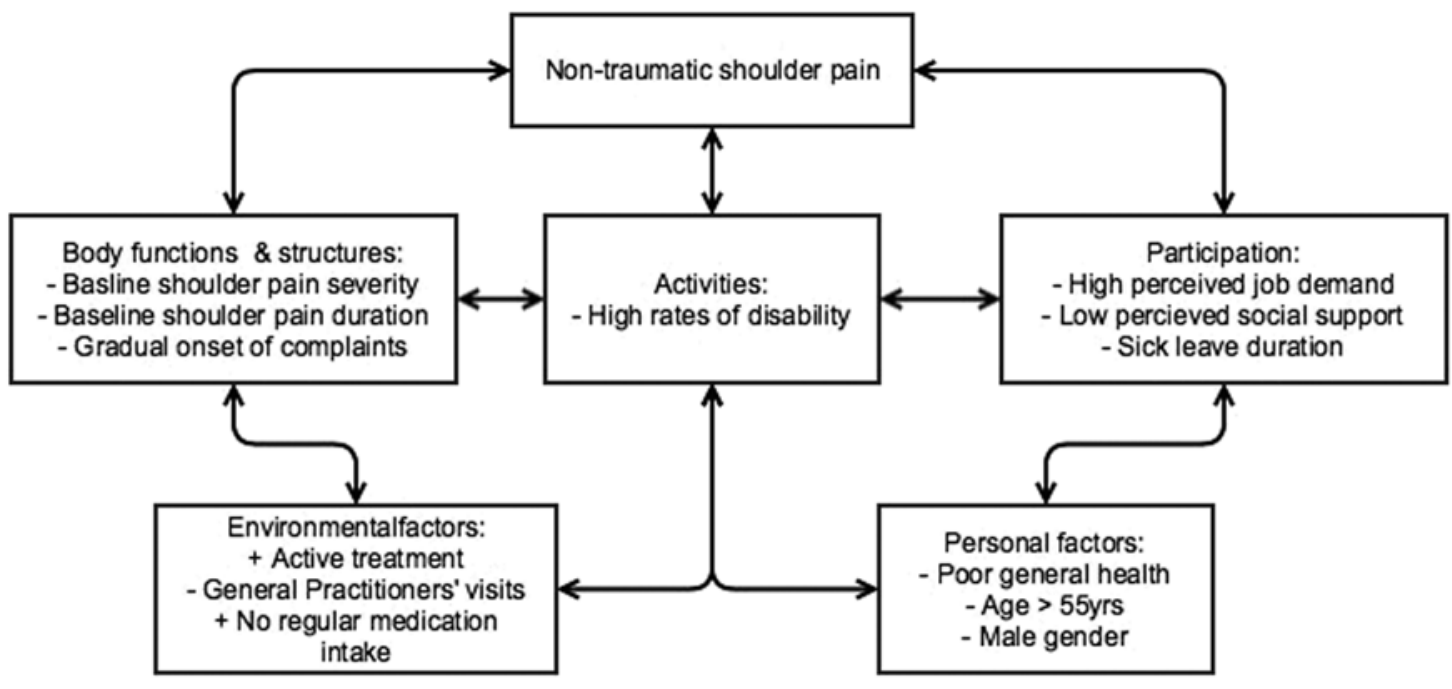

Fig. 2. The International Classification of Functioning, Disability and Health: Prognostic factors with moderate and strong evidence of having an enhancing (-) or reducing (+) effect on the possibility of developing chronic non-traumatic shoulder pain.

tice. The International Classification of Functioning, Disability and Health (ICF) is frequently used by clinicians in order to identify possible associations between functioning, participation, activities, and the patients' disease. These associations were consequently linked with environmental or personal factors. We integrated the prognostic factors with strong and moderate evidence into the ICF model (Fig. 2). In summary, baseline shoulder pain severity, baseline shoulder pain duration, and the gradual onset of complaints were categorized as associated body functions and structures, whereas high rates of disability as activities, high perceived job demand, low perceived social support, and sick leave duration were categorized as a problem in participation. Consequently, an active treatment policy and lack of regular medication intake were seen as environmen- 
tal factors that could have had a reducing effect on the odds for chronicity, whereas the amount of general practitioners' visits was categorized as a negative environmental factor for chronicity. Finally, poor general health, being above 55 years of age, and being male were considered to be negative personal factors for chronicity. Practicing clinicians, including pain physicians, can use the outcome of the present review for early identification of shoulder pain patients at risk for chronicity. This model allows health care professionals to analyze patient problems, to focus on specific targets, and to relate the salient disabilities to relevant and modifiable variables (15). In particular, this model can aid clinicians to address the patients' perspectives, control pain and disability, assess their job demand, job control, and social support, and thus enhance their participation in the decision-making process. Conversely in shoulder pain patients having risks for chronicity, practicing pain physicians can explain and emphasize the anticipated negative or positive outcome (i.e., natural history). The latter refers to reassurance, a concept gaining importance in the field of pain in general and one for which pain physicians can have a cardinal role. Still, studies examining the specific role of reassurance in the transition from acute to chronic pain are essentially lacking and require further study. Finally, pain physicians and other clinicians working with shoulder pain patients are advised to include the SPADI as a standard screening tool for shoulder pain patients to allow for a thorough assessment of the risk of developing chronic shoulder pain. The SPADI can be combined with history taking and specific questioning of the identified risk factors like social support, perception of job demands, and amount of visits to health care professionals as well as other risk factors.

In addition, it is often hypothesized that a more restrictive prescription of sick leave and pain medication may contribute to improved prognosis and may be introduced or at least reinforced by the physician. Consequently, a more targeted approach (e.g., advice regarding pain coping strategies) might lead to better patient outcomes in chronic shoulder pain patients. However, this needs to be confirmed by randomized controlled trials. Therefore, the results from this systematic review may help general practitioners provide patients with more accurate information on the expected course of their symptoms. Indeed, prognostic studies do not imply causality, and are therefore unsuitable for making conclusions regarding interventions. Consequently, the conclusions derived here are suitable for predicting long-term outcome only. These ICF model rather emphasizes the risk of sick leave in patients with shoulder pain, and may help to identify those who need additional attention. Therefore, the clinical usefulness of the developed prediction model should be established and an important goal for future study is to analyze from which interventions patients in the high risk categories benefit most. This has important implications for future interventions; whether it highlights the need for earlier intervention or reflects different natural histories of shoulder pain is a topic for further research.

\section{Limitations and Recommendations for Further Research}

To the best of our knowledge, this review was the first systematic overview of the prognostic factors for shoulder pain. However, this review has certain limitations that have to be taken into account in interpreting its results. There were 9 cohort studies with high methodological quality included in this systematic review. Therefore, this systematic review presented only strong and moderate evidence. However, because we excluded all low-quality studies, it was not possible to score results with weak evidence.

First, only studies published in English or Dutch were included in this review and consequently studies published in other languages might have been missed. However, the influence of language bias is disputed and its effect has not been established (16). Next, most of the excluded studies had a study population of patients with complaints at other body regions besides the shoulder region and did not report data for shoulder pain separately. Therefore, they were excluded, resulting in some potentially interesting, but missing, data. However, the present review did not demonstrate any relationship between the cause of shoulder pain and its prognosis. The complex interrelations between the shoulder and adjacent areas and the frequent occurrence of referred pain makes it difficult to form a clear definition or classification of shoulder problems. Some of the heterogeneity seen in the clinical characteristics of the study populations partly reflects the different exclusion criteria and definitions of the shoulder disorder used.

Psychosocial factors are often studied in chronic musculoskeletal disorders, such as low back pain and fibromyalgia. However, the use of such a questionnaire is limited in chronic shoulder pain populations, which gives rise to questions regarding the validity of the prognostic factors in all included studies and 
therefore potentially underestimates their impact. In addition, there is a need for cohort studies with a long follow-up period for at least 6 months, together with studies in which multivariate logistic statistical analyses are used. Finally, consensus on the ideal outcome parameters for analyzing prognosis would greatly strengthen evidence, as this would allow meta-analysis.

\section{Conclusion}

Clinicians can use an ICF-based model that could aid their decision-making in order to reduce chronicity. There was strong evidence that high scores on the SPADI questionnaire, more shoulder pain, and a long duration of complaints are associated with chronification of shoulder pain. Moderate evidence was found for other prognostic factors like male gender, age > 55 years, poor general health, a gradual onset of complaints, longer duration of sick leave, the perception of high job demand, low perceived social support, and the number of general practitioners visits.

\section{References}

1. Luime JJ, Koes BW, Hendriksen IJ, Burdorf A, Verhagen AP, Miedema HS, Verhaar JA. Prevalence and incidence of shoulder pain in the general population; a systematic review. Scandinavian Journal of Rheumatology 2004; 33:73-81.

2. Luime J, Koes BW, Miedem HS, Verhaar JA, Burdorf A. High incidence and recurrence of shoulder and neck pain in nursing home employees was demonstrated during a 2-year follow-up. Journal of Clinical Epidemiology 2005; 58:407-413.

3. Ryall C, Coggon D, Peveler R, Reading I, Palmer KT. A case-control study of risk factors for arm pain presenting to primary care services. Occup Med (Lond) 2006; 56:137-143.

4. Croft P, Pope D, Silman A. The clinical course of shoulder pain: prospective cohort study in primary care. Primary Care Rheumatology Society Shoulder Study Group. BM] 1996; 313:601-602.

5. van der Windt DA, Koes BW, Boeke AJ, Deville W, De Jong BA, Bouter LM. Shoulder disorders in general practice: Prognostic indicators of outcome. The British Journal of General Practice 1996; 46:519-523.

6. Kuijpers T, van der Windt DA, Boeke AJ, Twisk JW, Vergouwe Y, Bouter LM, van der Heijden GJ. Clinical prediction rules for the prognosis of shoulder pain in general practice. Pain 2006; 120:276-285.

7. Kuijpers T, van Tulder MW, van der Heijden GJ, Bouter LM, van der Windt DA. Costs of shoulder pain in primary care consulters: A prospective cohort study in The Netherlands. BMC Musculoskeletal Disorders 2006; 7:83.
8. Meislin RJ, Sperling JW, Stitik TP. Persistent shoulder pain: Epidemiology, pathophysiology, and diagnosis. American Journal of Orthopedics 2005; 34:5-9.

9. Redondo-Alonso L, Chamorro-Moriana G, Jimenez-Rejano J, Lopez-Tarrida P, Ridao-Fernandez C. Relationship between chronic pathologies of the supraspinatus tendon and the long head of the biceps tendon: Systematic review. BMC Musculoskeletal Disorders 2014; 15:377.

10. Struyf F, Meeus M. Current evidence on physical therapy in patients with adhesive capsulitis: What are we missing? Clinical Rheumatology 2014; 33:593-60o.

11. Kelley MJ, Shaffer MA, Kuhn JE, Michener LA, Seitz AL, Uhl TL, Godges JJ, McClure PW. Shoulder pain and mobility deficits: adhesive capsulitis. The Journal of Orthopaedic and Sports Physical Therapy 2013; 43:A1-A31.

12. Kelley MJ, McClure PW, Leggin BG. Frozen shoulder: Evidence and a proposed model guiding rehabilitation. The Journal of Orthopaedic and Sports Physical Therapy 2009; 39:135-148.

13. Treede RD, Jensen TS, Campbell JN, Cruccu G, Dostrovsky JO, Griffin JW, Hansson P, Hughes R, Nurmikko T, Serra J. Neuropathic pain: Redefinition and a grading system for clinical and research purposes. Neurology 2008; 70:1630-1635.

14. Moher D, Liberati A, Tetzlaff J, Altman DG. Preferred reporting items for systematic reviews and meta-analyses: The PRISMA statement. Annals of Internal Medicine 2009; 151:264-269, W264.

15. Steiner WA, Ryser L, Huber E, Uebelhart D, Aeschlimann A, Stucki G. Use of the
ICF model as a clinical problem-solving tool in physical therapy and rehabilitation medicine. Physical Therapy 2002; 82:1098-1107.

16. Kuijpers $T$, van der Windt DA, van der Heijden GJ, Bouter LM. Systematic review of prognostic cohort studies on shoulder disorders. Pain 2004; 109:420-431.

17. Bonde JP, Mikkelsen S, Andersen JH, Fallentin N, Baelum J, Svendsen SW, Thomsen JF, Frost P, Thomsen G, Overgaard E, Kaergaard A, Group PHS. Prognosis of shoulder tendonitis in repetitive work: A follow up study in a cohort of Danish industrial and service workers. Occupational and Environmental Medicine 2003; 60:E8.

18. Brox Jl, Brevik Jl. Prognostic factors in patients with rotator tendinosis (stage II impingement syndrome) of the shoulder. Scandinavian Journal of Primary Health Care 1996; 14:100-105.

19. Reilingh ML, Kuijpers T, Tanja-Harfterkamp AM, van der Windt DA. Course and prognosis of shoulder symptoms in general practice. Rheumatology 2008; 47:724-730.

20. Thomas E, van der Windt DA, Hay EM, Smidt N, Dziedzic K, Bouter LM, Croft PR. Two pragmatic trials of treatment for shoulder disorders in primary care: Generalisability, course, and prognostic indicators. Annals of the Rheumatic Diseases 2005; 64:1056-1061.

21. van der Windt DA, Kuijpers T, Jellema P, van der Heijden GJ, Bouter LM. Do psychological factors predict outcome in both low-back pain and shoulder pain? Annals of the Rheumatic Diseases 2007; 66:313-319. 